\title{
Quorum Sensing and Spoilage Potential of Psychrotrophic Enterobacteriaceae Isolated from Milk
}

\author{
Maurilio Lopes Martins, ${ }^{1}$ Uelinton Manoel Pinto $\left(\mathbb{D},^{2}\right.$ \\ Katharina Riedel, ${ }^{3}$ and Maria Cristina Dantas Vanetti ${ }^{4}$ \\ ${ }^{1}$ Department of Food Science and Technology, Federal Institute of Southeast of Minas Gerais, 36180-000 Rio Pomba, MG, Brazil \\ ${ }^{2}$ Food Research Center, Department of Food and Experimental Nutrition, Faculty of Pharmaceutical Sciences, \\ University of São Paulo, 05508-000 São Paulo, SP, Brazil \\ ${ }^{3}$ Institute of Microbiology, Ernst-Moritz-Arndt University of Greifswald, 17489, Germany \\ ${ }^{4}$ Department of Microbiology, Federal University of Viçosa, 36570-000 Viçosa, MG, Brazil
}

Correspondence should be addressed to Uelinton Manoel Pinto; uelintonpinto@usp.br

Received 19 April 2018; Revised 25 September 2018; Accepted 2 October 2018; Published 22 October 2018

Academic Editor: Frederick D. Quinn

Copyright (C) 2018 Maurilio Lopes Martins et al. This is an open access article distributed under the Creative Commons Attribution License, which permits unrestricted use, distribution, and reproduction in any medium, provided the original work is properly cited.

\begin{abstract}
The $16 \mathrm{~S}$ rDNA of six psychrotrophic Enterobacteriaceae isolated from cold raw milk were sequenced and the isolate 039 was identified as Pantoea sp., isolates 059, 068, and 071 were identified as Hafnia alvei, 067 was identified as Enterobacter sp., and 099 was identified as Aeromonas hydrophila. They presented different spoilage potentials in milk with A. hydrophila 099 being the most deteriorative. Only Pantoea sp. 039 was not able to induce the quorum sensing monitor strains of acyl homoserine lactones (AHLs). The hall gene, which encodes the AHL synthase in $H$. alvei, was identified in the isolates 059, 067, 068, and 071. After initial sequencing characterization and cloning, this gene showed its function by the heterologous synthesis of $\mathrm{N}$ hexanoyl-DL-homoserine lactone and N-3-oxohexanoyl-L-homoserine lactone in Escherichia coli. In addition to producing AHLs, A. hydrophila 099 produced AI-2 in higher level than the assay's positive control Vibrio harveyi BB120. Therefore, Enterobacteriaceae strains isolated from cooled raw milk produce a rich array of signaling molecules that may influence bacterial traits in the milk environment.
\end{abstract}

\section{Introduction}

Contamination of products with psychrotrophic microorganisms is a concern for the dairy industry since the majority of these products are maintained and distributed at temperatures permissive for the growth of these organisms. The diverse microorganisms categorized as psychrotrophic are ubiquitous in nature and can be isolated from soil, water, and vegetation [1].

Gram-negative bacteria usually account for more than $90 \%$ of the microbial population in cold raw milk that has been stored [2] and is composed mainly of psychrotrophic species of Pseudomonas, Achromobacter, Aeromonas, Serratia, Alcaligenes, Hafnia, Chromobacterium, Flavobacterium, and Enterobacter [3]. Most of these bacteria produce extracellular proteolytic and lipolytic enzymes that are secreted into milk and many of them are not completely inactivated by pasteurization or by ultrahigh temperature treatment [2]. The residual activities of these enzymes can reduce the sensorial quality and shelf life of processed milk products [4].

Many bacteria regulate the expression of some genes in response to the population size in a mechanism known as quorum sensing [5]. This mechanism allows the cells to control many of their functions and depending on the signal concentration the target genes are either activated or repressed [6].

Gram [7] has shown that some strains of Enterobacteriaceae isolated from foods produce acyl homoserine lactones (AHLs). These signaling molecules were detectable from naturally contaminated foods and from samples to which pure cultures have been added when levels of Enterobacteriaceae reached $10^{5}$ to $10^{7} \mathrm{CFU} / \mathrm{g}$. These levels are not uncommon in 
foods, which indicate that AHLs could be implicated in regulating phenotypes important for food spoilage. Additionally, it is important to understand the behavior of Enterobacteriaceae in foods since many foodborne pathogens belong to this family.

According to Christensen [8], several hydrolytic enzymes produced by a typical member of food spoilage microbiota are regulated by quorum sensing. They showed that quorum sensing is involved in the production of spoilage characteristics in situ on food products. AHL-production seems to be common among proteolytic psychrotrophic bacteria isolated from raw milk and the possibility of crosscommunication between these psychrotrophic microbiota types was suggested [9].

The understanding of the role that quorum sensing plays in the regulation of spoilage phenotypes in bacteria from milk is relevant and may be used to create new strategies to preserve dairy products. Therefore, the purpose of the present work was to elucidate which signaling molecules are produced by proteolytic psychrotrophic Enterobacteriaceae bacteria isolated from cooled raw milk and to relate the quorum sensing mechanism to the spoilage potential of these strains.

\section{Material and Methods}

2.1. Strains and Growth Conditions. The psychrotrophic strains and other bacteria used in the present study are listed in Table 1. Unless otherwise stated, these strains were grown at $30^{\circ} \mathrm{C}$ in Luria-Bertani (LB) medium. Solid media were routinely solidified with $1.4 \%$ agar. Antibiotics were added as required at final concentrations of $20 \mu \mathrm{g} / \mathrm{mL}$ for gentamicin and tetracycline, $50 \mu \mathrm{g} / \mathrm{mL}$ for spectinomycin, and $100 \mu \mathrm{g} / \mathrm{mL}$ for ampicillin.

\subsection{Identification of Psychrotrophic Strains Isolated from} Cooled Raw Milk. Psychrotrophic bacteria were isolated from cooled raw milk as described by Martins [10] and in order to confirm their identity we have used API ID32E (BioMérieux, Marcy-l'Etoile, France) for phenotypic characterization and $16 \mathrm{~S}$ rDNA sequencing for genotypic characterization.

For sequencing the rDNA 16S, PCR reaction consisted of $25 \mathrm{mM} \mathrm{MgCl}_{2}, 5.0 \mu \mathrm{L}$ of $10 \mathrm{X}$ buffer Ex Taq, $25 \mathrm{mM}$ deoxynucleotide triphosphates (dNTPs), $25 \mu \mathrm{M}$ of each primer, 1 U Ex Taq DNA polymerase, and 40 ng of DNA in a final volume of $50 \mu \mathrm{L}$. Primers described by Juretschko [11] are as follows: 616V, 5'AGAGTTTGATYMTGGCTC3', and 630R, 5'CAKAAAGGAGGTGATCC3', were synthesized by Microsynth (Zürich, Switzerland). PCR reactions were carried out in a T3 thermocycler (Biometra ${ }^{\circledR}$, Biolabo Scientific Instruments, Zürich, Switzerland). The M13 Universal and Reverse Primers were used to sequence the rDNA 16S genes cloned into pCR2.1-TOPO. Thereafter, the obtained sequences were used to search for similarity using the Ribosomal Database Project II (http://rdp.cme.msu.edu/ seqmatch/seqmatch_result.jsp?qvector $=204 \&$ depth $=0 \&$ currentRoot $=419 \&$ num $=20$ ).
2.3. Food Spoilage Potential and Production of Exoenzymes by Psychrotrophic Strains. To evaluate the food spoilage potential, samples of reconstituted skim milk powder, $12 \%$ $(\mathrm{w} / \mathrm{v})$, were inoculated with approximately $1.0 \times 10^{4} \mathrm{CFU} / \mathrm{mL}$ of Pantoea sp. 039, H. alvei 059, 068, or 071, Enterobacter sp. 067, or A. hydrophila 099. The samples were incubated at room temperature for $18 \mathrm{~h}$ and thereafter their spoilage ability in milk was checked visually.

Proteolytic activity was also determined by streaking the strains onto LB agar plates supplemented with $2 \%(\mathrm{w} / \mathrm{v})$ skim milk powder and on azocasein as previously prepared [4]. Prior to enzymatic assays, the method of Bradford [12] was used for quantitative protein determination using bovine serum albumin (BSA) as a standard.

Supernatant proteins obtained as crude extracts by centrifuging cultures grown on LB broth at $10,000 \mathrm{x} g$ for $20 \mathrm{~min}$ were analyzed by sodium dodecyl sulfate-polyacrylamide gel electrophoresis. After electrophoresis, the gels were stained with Coomassie brilliant blue. Exoprotease activities of culture supernatants from psychrotrophic strains were also analyzed by SDS-PAGE with $0.2 \%(\mathrm{w} / \mathrm{v})$ azocasein incorporated into the gel matrix (12\% polyacrylamide) as described before [4].

Lipolytic activity was determined by streaking the strains on medium 884 (Tween 80-Agar). Lipolytic activity on $p$ nitrophenyl palmitate was also investigated using $100 \mu \mathrm{L}$ bacterial supernatant from overnight cultures in LB or TYEP $[4,8]$.

2.4. Detection of AHL by Cross-Streaking. AHL-production was investigated by cross-streaking psychrotrophic strains that were grown overnight on LB agar plates against monitor strains as previously performed [9].

2.5. Extraction of AHL from Supernatants. An inoculum of $10^{4} \mathrm{CFU} / \mathrm{mL}$ of psychrotrophic strains was added to $250 \mathrm{~mL}$ of LB. Samples were incubated with aeration at $30^{\circ} \mathrm{C}$ for $20 \mathrm{~h}$ or until the population reaches $10^{9} \mathrm{CFU} / \mathrm{mL}$. Then, the cells were harvested by centrifugation at $10,000 \mathrm{x} g$ for $20 \mathrm{~min}$, and cell-free supernatants were used for AHL extraction [13].

2.6. Detection of AHL by Thin-Layer Chromatography (TLC). Twenty $\mu \mathrm{L}$ aliquots of extracts were loaded onto TLC plates as described in Pinto [9]. A volume of $150 \mathrm{~mL}$ of soft agar at $42^{\circ} \mathrm{C}$ was mixed with $30 \mathrm{~mL}$ of the monitor strain E. coli MT102 (pSB403) or C. violaceum CV026. The added soft agar of the appropriated monitor strain was dispensed onto TLC plate receiving a 2 to $3 \mathrm{~mm}$ thick layer. After $20 \mathrm{~min}$, the plate was put in an airproof box with a wet paper inside and incubated overnight at $30^{\circ} \mathrm{C}$.

The documentation was dependent on the monitor strain used. For C. violaceum CV026, the material was incubated until $48 \mathrm{~h}$ and the signal molecules could be identified by forming violet pigmented spots. When E. coli MT102 pSB403 was the monitor, the material was incubated overnight at $30^{\circ} \mathrm{C}$ and put into a dark box and the bioluminescence was detected with a highly sensitive photon-counting camera (C2400-40; Hamamatsu Photonics Herrsching, Germany). 


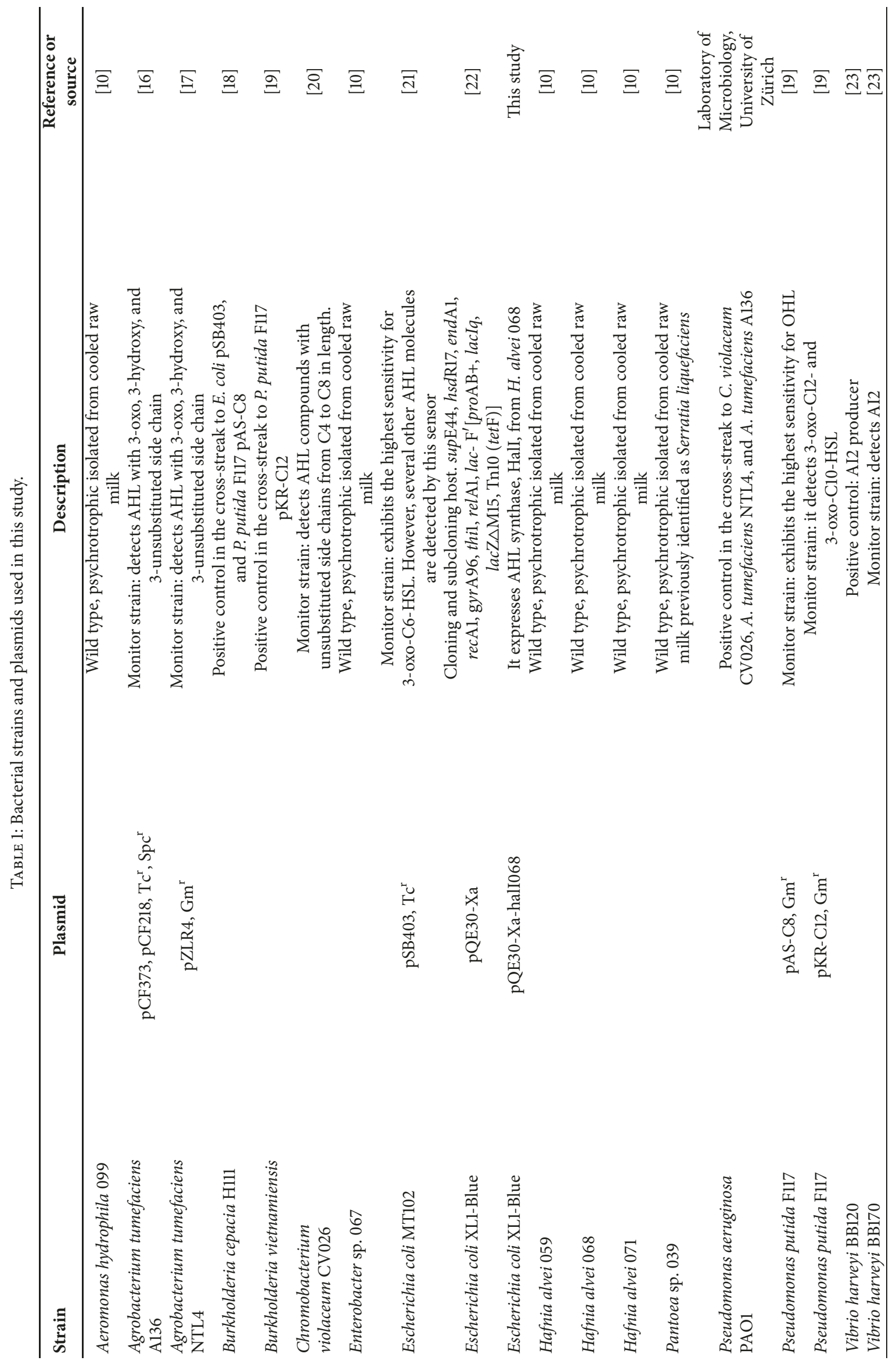


TABLE 2: Primers used to amplify halI and halR genes by PCR.

\begin{tabular}{lll}
\hline Primer & Sequence $\left(5^{\prime}-3^{\prime}\right)$ & Application \\
\hline $\begin{array}{l}\text { halI-F } \\
\text { halI-R }\end{array}$ & AACTGATTACACCAATGCAGT & Amplification of $h a l$ I \\
halI-bam & GGAATGCTTGAACTATTTGATG & $\begin{array}{l}\text { Amplification of } h a l \text { I } \\
\text { Amplification of } h a l \text { gene and } \\
\text { preparation for cloning in pQE-30Xa }\end{array}$ \\
halI-sac & ATTGGATCCTACACCAATGCAGTCTTAATT & $\begin{array}{l}\text { Amplification of } h a l \text { gene and } \\
\text { preparation for cloning in pQE-30Xa }\end{array}$ \\
halR-F & ATTGAGCTCATGCTTGAACTATTTGATGTC & Amplification of $h a l R$ \\
halR-R & CTT CAG GGA TGC CAT ATG TTT & Amplification of $h a l R$ \\
\hline
\end{tabular}

The introduced restriction sites for BamHI and SacI are underlined.

2.7. LC-MS Analysis of AHL Extracts from Bacterial Supernatants. One hundred and twenty $\mu \mathrm{L}$ of dichloromethane extracts from $400 \mathrm{~mL}$ of culture supernatant in LB medium were evaporated under a gentle stream of nitrogen. The residue was redissolved in $120 \mu \mathrm{L}$ of aqueous methanol $60 \%$ $(\mathrm{v} / \mathrm{v})$ and separated by reversed-phase LC-MS (C18 column, Grom-Sil 120 ODS-4 HE, 4.6 x 250 mm, Stagroma, Germany) under the following conditions: flow rate $1 \mathrm{~mL} / \mathrm{min}$; solvent A: UV-treated $\mathrm{H}_{2} \mathrm{O}$ and $0.1 \%$ formic acid; solvent $\mathrm{B}$ : acetonitrile $(\mathrm{ACN})$ and $0.1 \%$ formic acid, and it was subsequently analyzed by mass spectrometry (LCQ Duo Mass Spectrometer, Thermoquest, Finnigan) equipped with an electrospray source. The following gradient was applied: solvent B from $25 \% \mathrm{ACN}$ to $100 \%$ in $20 \mathrm{~min}$, isocratic, $5 \mathrm{~min}$.

2.8. DNA Manipulations, PCR Reactions, and Sequencing of hall and halR Genes. Cloning, restriction enzyme analysis, and transformation of $E$. coli were performed using established procedures [14]. To amplify the AHL synthase gene (halI) and the AHL receptor gene halR by PCR, the reaction consisted of $25 \mathrm{mM} \mathrm{MgCl}_{2}, 5.0 \mu \mathrm{L}$ of $10 \mathrm{X}$ buffer Ex Taq, 25 $\mathrm{mM}$ deoxynucleotide triphosphates (dNTPs), $25 \mu \mathrm{M}$ of each primer, 1 U Ex Taq DNA polymerase, and 40 ng of DNA from $H$. alvei 068 in a final volume of $50 \mu \mathrm{L}$. Primers based on the sequences of hall and halR genes (GenBank accession number AF503776) of $H$. alvei were constructed (see Table 2) and synthesized by Microsynth (Zürich, Switzerland). PCR reactions were carried out in a T3 thermocycler (Biometra ${ }^{\circledR}$, Biolabo Scientific Instruments, Zürich, Switzerland).

The M13 Universal and Reverse Primers were used to sequence hall and halR genes cloned into pCR2.1-TOPO.

2.9. Cloning and Heterologous Expression of AHL Synthase (HalI) of $H$. alvei 068 in $p Q E-30 X a$. Once the complete sequence of the hall gene was obtained, primers were designed to amplify the halI open reading frame (ORF) by PCR using the bacterial genomic DNA as a template and TaKaRa Ex Taq polymerase (see Table 2). Primers generated BamHI and SacI sites at the 5' and 3' ends of the amplicons, respectively (see Table 2). The DNA amplicon, $660 \mathrm{bp}$, containing the hall structural gene was digested with BamHI and SacI and ligated into vector pQE-30Xa (Qiagen), previously cut with the same restriction enzymes. This plasmid harboring the ORF of halI inserted downstream of the T5 promoter was named pQE-30Xa-halI068. Plasmid pQE-30Xa-halI068 was transformed into the expression strain E. coli XL1-Blue.

For overproduction of HalI, E. coli XL1-Blue cells carrying pQE-30Xa-halI068 were grown in dYT medium (tryptone $1.6 \%$, yeast extract $1.0 \%, \mathrm{NaCl} 0.5 \%$, and glucose $0.2 \%$ ) containing ampicillin $\left(100 \mu \mathrm{g} \mathrm{mL}^{-1}\right)$ at $37^{\circ} \mathrm{C}$ under vigorous shaking. At an optical density at $600 \mathrm{~nm}$ of 0.5 , isopropyl- $\beta$ D-thiogalactopyranoside (IPTG) was added to the culture to a final concentration of $1 \mathrm{mM}$. After $5 \mathrm{~h}$ incubation at $37^{\circ} \mathrm{C}$, the cells were collected by centrifugation at 10,000 $\mathrm{x} g$ for 30 $\mathrm{min}$ and resuspended in $50 \mathrm{mM}$ Tris- $\mathrm{HCl}$ ( $\mathrm{pH} \mathrm{8.0)}$. Then, 3 $\mu \mathrm{L}$ of cell suspension were loaded onto SDS-PAGE (15\%) in order to detect HalI overexpression.

2.10. Detection, Extraction, and Characterization of AHL Produced by HalI. AHL-production was investigated by crossstreaking E. coli XL1-Blue pQE-30Xa-halI068 that was grown overnight on dYT agar plates supplemented with $1 \mathrm{mM}$ IPTG against E. coli pSB403 or C. violaceum CV026.

In order to extract $\mathrm{AHL}, 10^{4} \mathrm{CFU} / \mathrm{mL}$ of E. coli XL1-Blue pQE-30Xa-halI068 were inoculated in $250 \mathrm{~mL}$ of dYT. At an optical density at $600 \mathrm{~nm}$ of 0.5 . IPTG was added to the culture to a final concentration of $1 \mathrm{mM}$. The samples were incubated with aeration at $30^{\circ} \mathrm{C}$ up to 48 hours. Then, the cells were harvested by centrifugation at $10,000 \times \mathrm{g}$ for $20 \mathrm{~min}$, and cell-free supernatants were used to extract AHL [13].

Detection of AHL by Thin-Layer Chromatography (TLC) was done as described in item 2.6, as well as the chemical characterization by LC-MS analysis of AHL molecules present in the extracts from bacterial supernatants (item 2.7).

2.11. Autoinducer 2 Production in Psychrotrophic Strains. Psychrotrophic strains were grown overnight with aeration at $30^{\circ} \mathrm{C}$ on LB medium. Cell-free culture supernatants were prepared by removing the cells from the growth medium by centrifugation at $10,000 \times \mathrm{g}$ for $20 \mathrm{~min}$. The cleared culture supernatants were passed through $0.2 \mu \mathrm{m}$ filters and stored at $-20^{\circ} \mathrm{C}$. As a positive control, V. harveyi $\mathrm{BB} 120$ was grown overnight at $30^{\circ} \mathrm{C}$ with aeration in $\mathrm{AB}$ medium [15], which is optimal for Vibrio species and commonly used in AI-2 assays. It is composed of $\mathrm{NaCl} 0.30 \mathrm{M}, \mathrm{MgSO}_{4} 0.05 \mathrm{M}$, vitamin-free casamino acids $0.2 \%$, and $\mathrm{pH} 7.5$ (adjusted with $\mathrm{KOH}$ ). The medium was sterilized and cooled, and $10 \mathrm{ml}$ of sterile $1 \mathrm{M}$ potassium phosphate ( $\mathrm{pH} 7.0$ ), $10 \mathrm{~mL}$ of $0.1 \mathrm{M} \mathrm{L}$-arginine, 
TABLE 3: Identification of Enterobacteriaceae isolated from cooled raw milk.

\begin{tabular}{lcc}
\hline Isolate & API ID32E & rDNA 16S \\
\hline 039 & $\mathrm{Nd} *$ & Pantoea sp. \\
059 & $\mathrm{Nd}$ & Hafnia alvei \\
067 & Enterobacter cloacae & Enterobacter sp. \\
068 & Hafnia alvei & Hafnia alvei \\
071 & Hafnia alvei & Hafnia alvei \\
099 & Aeromonas hydrophila & Aeromonas hydrophila \\
\hline
\end{tabular}

*Nd: not determined (inconclusive results).
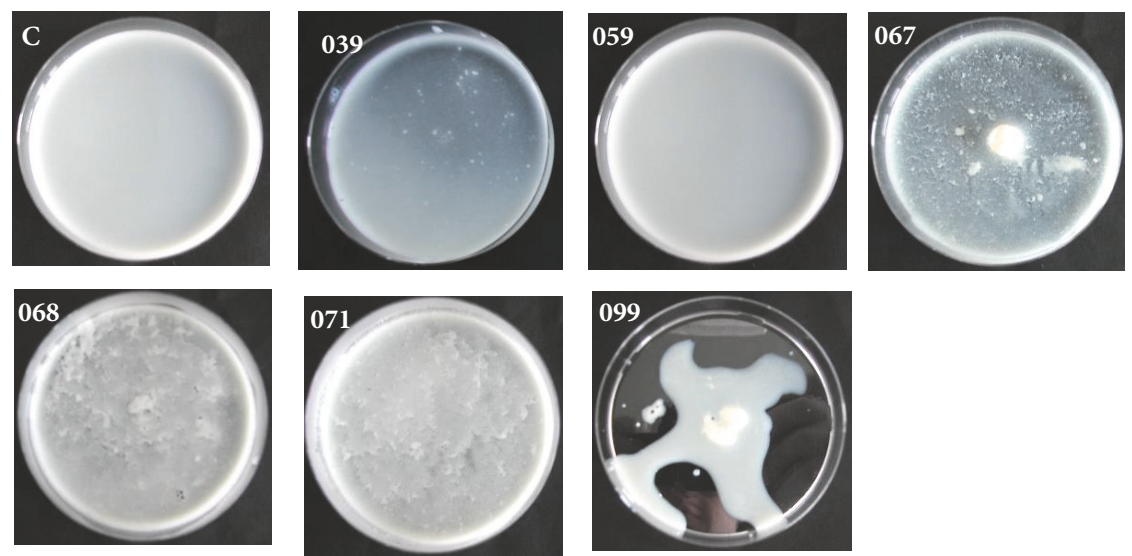

Figure 1: Spoilage ability of psychrotrophic strains inoculated in reconstituted skim milk powder, 12\% (w/v). (C) Negative control, milk sample not inoculated, (039) Pantoea sp., (059) H. alvei, (067) Enterobacter sp., (068) H. alvei, (071) H. alvei, and (099) A. hydrophila.

$20 \mathrm{~mL}$ of glycerol, $1 \mathrm{~mL}$ of $10 \mu \mathrm{g} / \mathrm{mL}$ riboflavin, and $1 \mathrm{~mL}$ of $1 \mathrm{mg} / \mathrm{mL}$ thiamine per $\mathrm{L}$ were added. Cell-free culture supernatants from $V$. harveyi BB120 were prepared from overnight culture by centrifugation at $10,000 \times \mathrm{g}$ for $20 \mathrm{~min}$. Aliquots of $10 \mu \mathrm{L}$ of cell-free culture fluids were added to 96 well microtiter plates. The monitor strain, V. harveyi BB170, was grown with aeration for $16 \mathrm{~h}$ at $30^{\circ} \mathrm{C}$ in $\mathrm{AB}$ medium and diluted as 1:5.000 into fresh $\mathrm{AB}$ medium. Aliquots of 90 $\mu \mathrm{L}$ of diluted cells were added to wells containing the $10 \mu \mathrm{L}$ psychrotrophic strains cell-free culture fluids. Positive control wells contained $10 \mu \mathrm{L}$ of cell-free culture fluid from $V$. harveyi $\mathrm{BB} 120$ and negative control wells contained $10 \mu \mathrm{L}$ of sterile growth medium (LB or AB). Microtiter dishes were shaken in a rotary shaker at $175 \mathrm{RPM}$ at $30^{\circ} \mathrm{C}$. Bioluminescence was measured using the KC4 (Bio-Tek Instruments, Highland Park, Box 998, Vermont, USA).

\section{Results and Discussion}

3.1. Identity of the Psychrotrophic Strains Isolated from Cooled Raw Milk. The identity of the strains characterized in this study is shown in Table 3 . We were unable to show the species level for isolate 039 (see Table 3), identified only as Pantoea sp. by the $16 \mathrm{~S}$ rDNA sequencing. The biochemical characterization by using the API ID32E was inconclusive for isolates 039 and 059. Pinto [9] showed that these psychrotrophic isolates were able to induce quorum sensing biosensor strains, but further characterization of the quorum sensing signal molecules repertoire and their spoilage potential was not performed. Additionally, we decided to characterize these isolates because they belong to the Enterobacteriaceae family, as well as their prevalence in Brazilian milk [24].

\subsection{Spoilage Potential and Production of Exoenzymes. The} strains evaluated in this study showed different abilities to spoil milk samples as shown in Figure 1. As it can be observed, A. hydrophila 099 was the most deteriorative, whereas Pantoea sp. 039 had lower ability to spoil milk, as well as $H$. alvei 059 (see Figure 1).

Bacterial spoilage causes significant economic losses for the dairy industry, and different psychrotrophic strains can show different spoilage potentials as confirmed in this and many other studies $[1,2,4]$. Additionally, many works have shown the spoilage potential of Pseudomonas spp. isolated from milk samples, but only a few have investigated the role that other species have on milk deterioration [2, 25], which explains our interest in characterizing isolates that belong to the Enterobacteriaceae family.

The proteolytic activity of some extracellular enzymes of A. hydrophila has been recognized and it is considered to play a major role in the virulence and pathogenicity of this bacterium [26]. Besides, Vivas [27] showed that this microorganism can produce and secrete proteases able to cleave milk proteins. According to Cousin [28], proteases produced by Aeromonas are able to degrade $\alpha-, \beta-, \kappa^{-}$, and $\gamma$-casein as well as the whey proteins. Khajanchi [29] have shown the involvement of quorum sensing in the control 

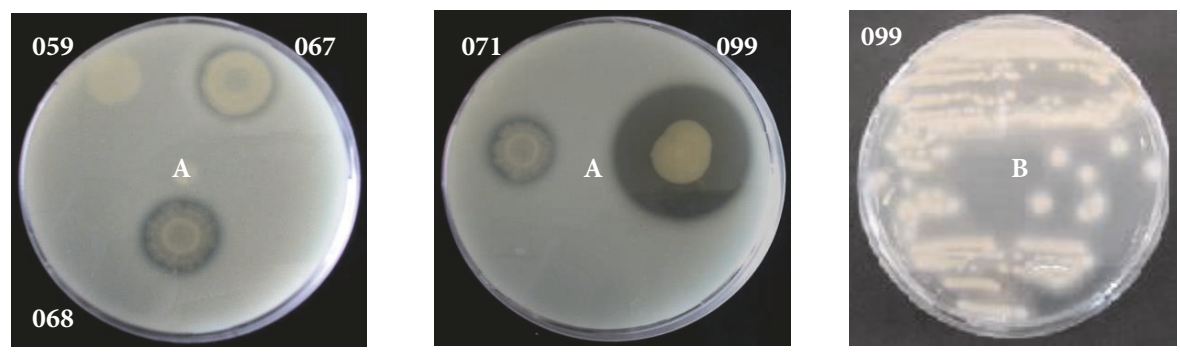

Figure 2: (A) Proteolytic activity on LB agar supplemented with 2\% (w/v) skim milk powder. Clearing zones are indicative of protease activity. (059) H. alvei, (067) Enterobacter sp., (068) H. alvei, (071) H. alvei, and (099) A. hydrophila. (B) Lipolytic activity after growth of A. hydrophila 099 on Tween 80 -Agar for $48 \mathrm{~h}$ at $30^{\circ} \mathrm{C}$. Precipitation zones are indicative of lipase activity.

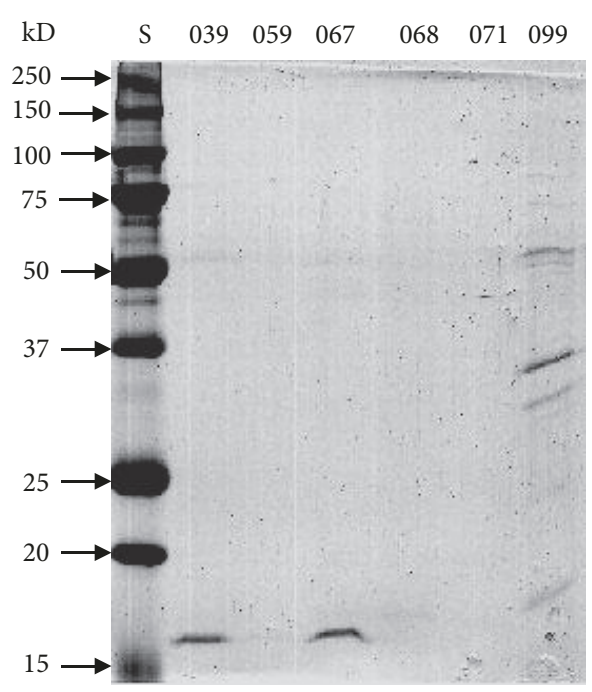

(a)

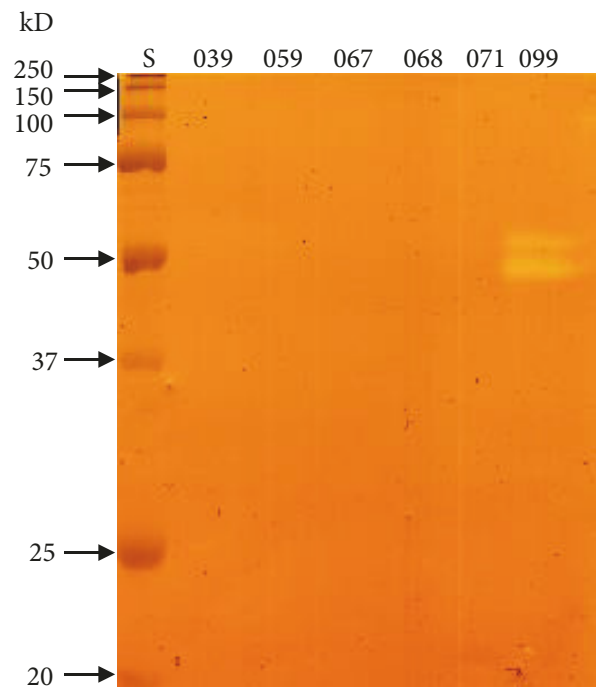

(b)

FigURE 3: SDS-PAGE (a) and zymogram azocasein (b) gel (12\%) showing protease production by psychrotrophic strains after growth in LB medium. Lines: (S) standards of molar mass, (039) Pantoea sp. (059), H. alvei, (067) Enterobacter sp., (068) H. alvei, (071) H. alvei, and (099) A. hydrophila.

of protease production and in vivo virulence of a strain of clinical significance of $A$. hydrophila.

All three strains of $H$. alvei presented different spoilage potentials underscoring the genetic variability of these isolates (see Figure 1). According to Bruhn [30], H. alvei was the dominant member of Enterobacteriaceae in vacuum-packed meat, possibly inducing food quality-relevant phenotypes in other bacterial species in the same environment. In addition to the possibility of inducing phenotypes in other bacterial species, two of our strains were able to spoil milk samples (see Figure 1).

Although Enterobacter sp. is normally isolated from raw and pasteurized milk and butter [28], it is not considered a potent dairy spoiler bacterium. However, in this study, it was verified that strain 067 presented a potential to spoil reconstituted skim milk samples (see Figure 1).

In order to confirm the proteolytic nature of the bacterial isolates, we streaked them onto LB agar plates supplemented with $2 \%$ skim milk powder and it was once again verified that they had different abilities to produce proteolytic enzymes able to cleave casein (see Figure 2). These results confirmed that $A$. hydrophila produced the highest amount of exoproteases compared to the other strains judging by the diameter of the clearing zone (see Figure 2). H. alvei 059 and Pantoea sp. 039 were unable to hydrolyze casein in this assay, confirming our previous results (see Figure 1).

We then sought to verify the extracellular proteolytic activity in supernatant of cultures grown on LB and TYEP broth media. However, strains 039, 059, 067, 068, and 071 did not produce detectable levels in this assay. It is likely that the azocasein is not a good substrate for determination of proteolytic activity produced by these strains or that they do not produce these enzymes on the broths chosen for the assays. Their ability to spoil milk shown in Figures 1 and 2 should not be neglected.

In contrast, strain 099 showed proteolytic activity of 0.131 units $/ \mathrm{h} / \mu \mathrm{g}$ of protein in TYEP. Many extracellular proteins were observed in the supernatant obtained from A. hydrophila 099 (see Figure 3(a)), and two of them had proteolytic activity on SDS-PAGE supplemented with $2 \%$ 
TABLE 4: Activation of the AHL monitor strains in cross-streak experiments.

\begin{tabular}{|c|c|c|c|c|c|c|}
\hline \multirow{2}{*}{ Isolate and controls } & \multicolumn{6}{|c|}{ Monitor strains } \\
\hline & CV 026 & pSB403 & F117 (pAS-C8) & F117 (pKR-C12) & A 136 & NTL4 \\
\hline Pantoea sp. 039 & - & - & - & - & + & ++ \\
\hline H. alvei 059 & +++ & +++ & ++ & - & +++ & +++ \\
\hline Enterobacter sp. 067 & + & ++ & - & - & + & ++ \\
\hline H. alvei 068 & +++ & +++ & ++ & - & +++ & +++ \\
\hline H. alvei 071 & +++ & +++ & + & - & +++ & +++ \\
\hline A. hydrophila 099 & ++ & ++ & + & - & + & +++ \\
\hline B. cepacia H111 & $\mathrm{Nd}$ & +++ & +++ & $\mathrm{Nd}$ & $\mathrm{Nd}$ & $\mathrm{Nd}$ \\
\hline B. vietnamiensis & $\mathrm{Nd}$ & $\mathrm{Nd}$ & $\mathrm{Nd}$ & +++ & $\mathrm{Nd}$ & $\mathrm{Nd}$ \\
\hline P. aeruginosa $\mathrm{PAO} 1$ & +++ & $\mathrm{Nd}$ & $\mathrm{Nd}$ & $\mathrm{Nd}$ & +++ & +++ \\
\hline
\end{tabular}

The six monitor strains were cross-streaked against different psychrotrophic strains on LB agar plates. Following up to 48 hours of incubation at $30^{\circ} \mathrm{C}$, the production of violacein by C. violaceum CV026, bioluminescence by E. coli pSB403, green fluorescent protein gfp (ASV) by P. putida F117, and $\beta$-galactosidase activity by A. tumefaciens A136 and NTL4 was visualized as described in the Material and Methods. Levels of activation are indicated as follows: +++, strong activation, diffusion of AHL of $>1 \mathrm{~cm}$; ++, activation, diffusion of AHL of 0.5 to $1 \mathrm{~cm}$; +, weak activation, diffusion of AHL of $<0.5 \mathrm{~cm}$; -, no detectable activation. Nd: not determined.

azocasein (see Figure 3(b)). Production of both serine protease and metalloprotease activities in A. hydrophila is under the control of quorum sensing mechanism [31]. However, Ponce-Rossi [32] challenged this idea when using a quorum sensing defective strain of $A$. hydrophila that continued to produce proteases, although at low levels.

No proteolytic activity was observed in the supernatant of the other strains grown in LB broth (see Figure 3(b)). Since previous data show that isolates 067,068 , and 071 present proteolytic activity in milk (see Figures 1 and 2), the effect of medium components should be evaluated in a future study to better clarify the involvement of environmental parameters on the protease production by these strains.

3.3. Lipase. In this study, only strain 099 showed lipolytic activity of 1.104 units $/ \mathrm{h} / \mu \mathrm{g}$ protein in TYEP medium. This activity was confirmed on Tween 80-Agar (see Figure 2B). The other strains did not present detectable lipase levels on this medium. According to Brumlik and Buckley [33], among extracellular enzymes released by A. hydrophila, a glycerophospholipid-cholesterol acyltransferase (GCAT) has been described and characterized. Lipolytic activity of other A. hydrophila strains has also been verified by Ponce-Rossi [32].

3.4. Detection of AHL Signaling Molecules. The tested psychrotrophic proteolytic strains induced many of the biosensor strains, as shown in Table 4 . As we used a range of different AHL monitor systems, it is possible that we have covered a wide range of known AHLs. Other members of Enterobacteriaceae isolated from food sources have been shown to produce signaling AHL molecules $[9,20]$.

Strains 059,068 , and 071 of $H$. alvei produced higher amounts of AHL than the others once they were able to strongly induce the monitor strains (see Table 4). Pinto [9] demonstrated that AHL-production is common among psychrotrophic bacteria isolated from milk and suggested that quorum sensing may play an important role in the spoilage of this product.
3.5. Characterization of AHL Molecules by TLC Analyses. The results from the TLC plates confirmed those obtained on the cross-streak experiment. Accordingly, no response to the extract prepared from Pantoea sp. 039 was observed on the TLCs revealed with E. coli pSB403 or C. violaceum CV026 (see Figures 4(b) and 5(b)). Different amounts of AHLs were detected on the TLC plates for the other strains (see Figures 4 and 5). For instance, the strains Enterobacter 067 and $A$. hydrophila 099 produced less amount of AHL compared to $H$. alvei 059, 068, and 071, since it was necessary to load higher volumes of AHL extracts onto the TLC plate in order to detect production of bioluminescence by E. coli pSB403 (see Figures 4(a) and 4(c)). Besides, the extracts obtained from Enterobacter 067 and A. hydrophila 099 were not able to induce C. violaceum CV026 (see Figures 5(a) and 5(b)).

Interestingly, we observed degradation products of $\mathrm{N}$ (dodecanoyl)-L-homoserine lactone (DHL) on TLC plates (see Figures 4(a) and 4(c)) which suggests high sensitivity of this AHL molecule to the experimental conditions. C. violaceum CV026 was unable to detect $\mathrm{N}$-(3-oxohexanoyl)L-homoserine lactone (OHHL) (see Figure 5), highlighting the importance of multiple AHL sensors systems to detect a broader range of AHL molecules.

3.6. Characterization of AHL Molecules by Liquid Chromatography-Mass Spectrometry (LC-MS). Isolates 059, 068, 071, and 099 produced different AHL molecules (see Table 5). However, it was not possible to detect any AHL molecule from the AHL extract of Enterobacter sp. 067, even though it induced the biosensors in the cross-streak assay and on the TLCs.

$H$. alvei isolates 059,068 , and 071 produced 3-oxo-C6HSL, C6-HSL, and 3-oxo-C8-HSL, whereas C8-HSL was produced by $H$. alvei 059 and 071 (see Table 5). In the experimental conditions adopted, 3-oxo-C6-HSL was the main AHL produced by $H$. alvei strains. This result agrees with those from Bruhn [30] who verified that this same HSL was predominant among four AHLs produced by $H$. alvei isolated from vacuum-packed meat. However, Hou [34] detected 


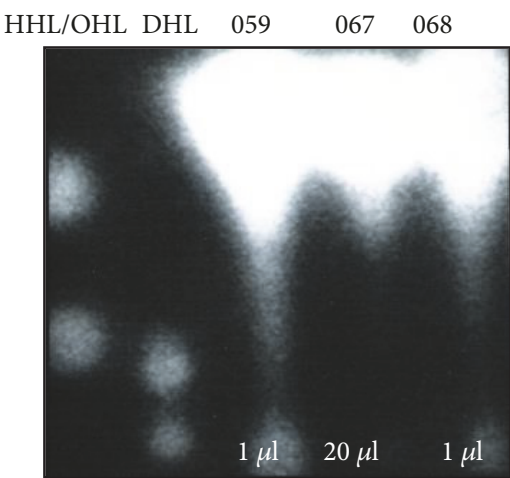

(a)

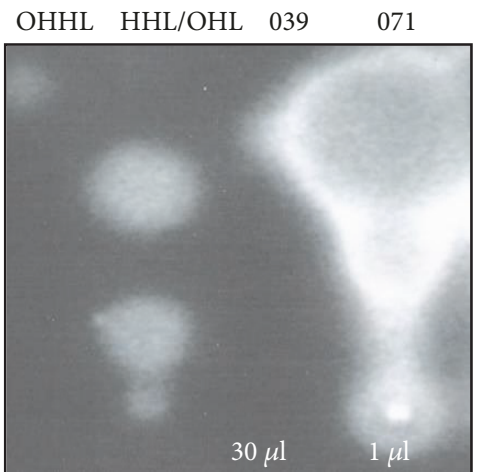

(b)

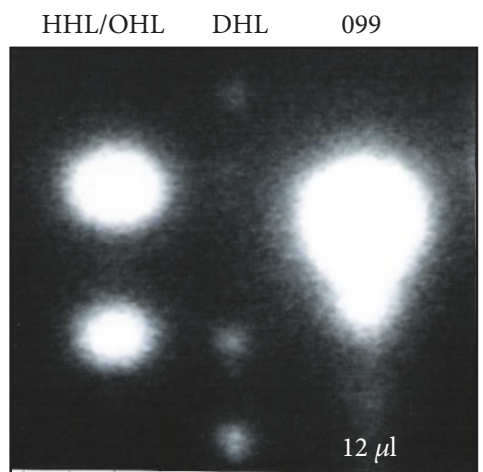

(c)

FIGURE 4: Representative thin-layer chromatograms of the signal molecules present in cell-free supernatants of Enterobacteriaceae strains isolated from cooled raw milk and cultivated in LB medium. The spots were detected with E. coli pSB403 reporter strain. Standards: N(hexanoyl)-DL-homoserine lactone (HHL); N-(octanoyl)-L-homoserine lactone (OHL); N-(dodecanoyl)-L-homoserine lactone (DHL); N(3-oxohexanoyl)-L-homoserine lactone (OHHL). (059) H. alvei, (067) Enterobacter sp., (068) H. alvei, (039) Pantoea sp., (071) H. alvei, and (099) A. hydrophila.

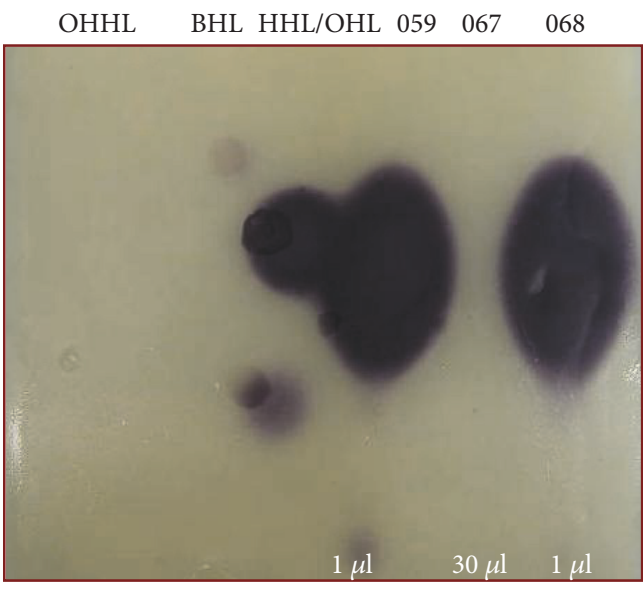

(a)

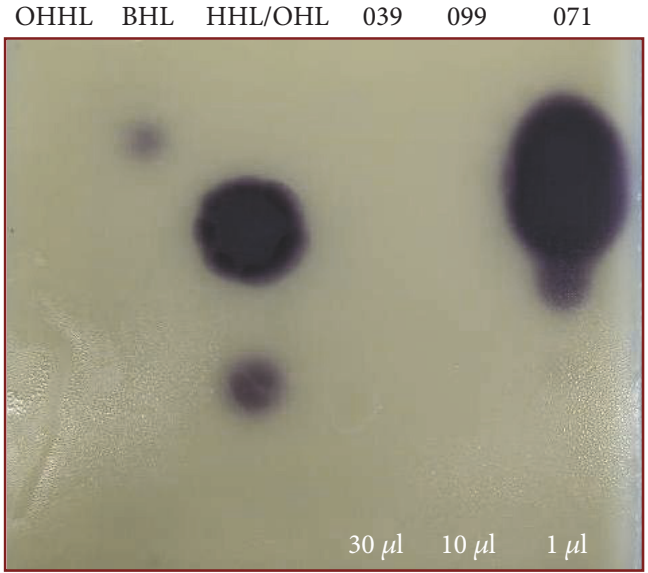

(b)

FIGURE 5: Representative thin-layer chromatograms of the signal molecules present in cell-free supernatants of Enterobacteriaceae isolated from cooled raw milk and cultivated in LB medium. The spots were detected with C. violaceum CV026 reporter strain. Standards: N-(3oxohexanoyl)-L-homoserine lactone (OHHL); N-(butanoyl)-L-homoserine lactone (BHL); N-(octanoyl)-L-homoserine lactone (OHL); N(hexanoyl)-DL-homoserine lactone (HHL). (059) H. alvei, (067) Enterobacter sp., (068) H. alvei, (039) Pantoea sp., (099) A. hydrophila, and (071) H. alvei.

C4-HSL, C6-HSL, and 3-oxo-C8-HSL in culture supernatants of $H$. alvei $\mathrm{H} 4$ isolated from spoiled sea cucumber, revealing the diversity of signaling molecules in $H$. alvei species.

On the other hand, A. hydrophila 099 produced C4-HSL and C6-HSL (see Table 5), confirming the results of Swift [35] and Nagar [36] who demonstrated that A. hydrophila produces C4-HSL as the major AHL molecule. Quorum sensing in this pathogen has been associated with regulation of biofilm development $[37,38]$ and exoprotease production [31].

H. alvei produced a molecule that presented mass spectrum similar to 3-hydroxy-C4-HSL and 3-hydroxy-C12-HSL, whereas A. hydrophila 099 probably produced C5-HSL (see Table 5). However, the identity of these molecules was not confirmed since standards of these compounds were not available to determine their mass spectrum and retention time.

Characterization of different AHLs by LC-MS reinforces the data obtained in the cross-streak experiments in which different biosensor strains were induced in this study. Each AHL biosensor relies on a specific LuxR homologue, thus displaying specificity towards its cognate AHL and in some cases to closely related AHLs [39].

3.7. halI and halR Gene Characterization by PCR and Sequencing. Amplified products of expected size, $660 \mathrm{bp}$ or 751 $\mathrm{bp}$, were obtained for halI and halR genes, respectively. Additionally, the halI gene was detected in all strains of $H$. alvei used in this study as well as in Enterobacter sp. 067. The halI gene of $H$. alvei 068 and 071 showed $99 \%$ identity with 
TABLE 5: Summary of identification by high-performance liquid chromatography positive electrospray ionization (ESI ${ }^{+}$-) MS of AHLs produced by $H$. alvei 059, 068, and 071, Enterobacter sp. 067, and A. hydrophila 099.

\begin{tabular}{|c|c|c|c|c|c|c|c|c|}
\hline \multirow[t]{2}{*}{ Standard } & \multirow[t]{2}{*}[\mathrm{M}+\mathrm{H}]{$^{+1}$} & \multicolumn{7}{|c|}{ Retention time of AHL molecules [min] } \\
\hline & & Standard mix Calibration $^{1}$ & 067 & 068 & 071 & 099 & Standard mix Calibration & 059 \\
\hline C4-HSL & 172 & 5.5 & -3 & - & - & 5.8 & 4.29 & - \\
\hline 3-hydroxy-C4-HSL & 188 & $\mathrm{Nd}^{2}$ & - & 4.6 & - & - & $\mathrm{Nd}$ & - \\
\hline C5-HSL & 186 & $\mathrm{Nd}$ & - & - & - & 7.8 & $\mathrm{Nd}$ & - \\
\hline 3-Oxo-C6-HSL & 214 & 6.6 & - & 6.5 & 6.6 & - & 4.57 & 4.55 \\
\hline C6-HSL & 200 & 10.9 & - & 10.9 & 11.0 & 10.9 & 9.69 & 9.45 \\
\hline 3-Oxo-C8-HSL & 242 & 12.5 & - & 12.5 & 12.5 & - & 11.18 & 11.16 \\
\hline C8-HSL & 228 & 15.3 & - & - & 15.4 & - & 14.26 & 14.2 \\
\hline 3- hydroxy-C12-HSL & 300 & $\mathrm{Nd}$ & - & 17.2 & 17.2 & - & $\mathrm{Nd}$ & - \\
\hline C10-HSL & 256 & 18.6 & - & - & - & - & 17.59 & - \\
\hline 3-Oxо-C12-HSL & 298 & 19.0 & - & - & - & - & $\mathrm{Nd}$ & - \\
\hline
\end{tabular}

${ }^{1}[\mathrm{M}+\mathrm{H}]^{+}$, mass to charge rate. ${ }^{2} \mathrm{Nd}$, not determined. ${ }^{3}$ Nothing found.

one another. The same result was observed when the halI and halR genes of $H$. alvei 068 were compared to halI and halR genes of Enterobacter sp. 067 (see Figure 6). However, when sequences of hal gene of $H$. alvei 068 and $H$. alvei 059 were aligned, they showed $75 \%$ identity with each other. Differences in the sequences of these genes may account for the differences in the phenotypic tests we have observed, including the different AHL profiles.

3.8. Sequencing and Overexpression of halI in E. coli XL1-Blue. In order to confirm which AHL molecules are synthesized by HalI, halI gene from $H$. alvei 068 was sequenced, cloned, and overexpressed in E. coli XL1-Blue. This gene comprised $660 \mathrm{bp}$ and coded for a protein of 216 amino acids. Based on electrophoretic mobility, the molecular mass of this enzyme was determined to be approximately $16 \mathrm{kDa}$ and was soluble in the conditions used in this study. Size chain of HalI was in agreement with LuxI-type proteins that usually contain between 194 and 226 amino acids [40].

3.9. HalI Produces AHL Molecules Ectopically in E. coli. Cross-streak between $E$. coli XL1-Blue harboring pQE-30Xahall and biosensors E. coli pSB403 and C. violaceum CV026 was performed confirming induction of both monitor strains, which indicates successful expression and activity of HalI in $E$. coli. We then analyzed supernatant extracts of E. coli XL1-Blue harboring PQE-30Xa-halI cultured in LB medium confirming the induction of E. coli pSB403 and C. violaceum CV026 on the TLC assays (see Figure 7). The spots observed on TLC where E. coli pSB403 was used as biosensor presented the same retention factor (rf) of 3-oxo-C6-HSL (see Figure 7), while a smaller spot close to C6-HSL was detected on TLC developed with C. violaceum CV026 (see Figure 7). These results indicated that halI gene codes for an enzyme able to synthesize 3-oxo-C6-HSL and C6-HSL.

Besides characterizing the products of HalI expression by TLC, we have also analyzed the extracts by LC-MS confirming the production of C6-HSL and 3-oxo-C6-HSL (see Figure 8). Interestingly, the parental $H$. alvei strain produced additional molecules as shown on Table 5. It is
TABLE 6: Detection of autoinducer 2 in supernatant of LB medium inoculated with psychrotrophic strains.

\begin{tabular}{lc}
\hline Strains and medium & Luminescence at $175 \mathrm{~nm} *$ \\
\hline Pantoea sp. 039 & $1973 \pm 345$ \\
H. alvei 059 & $2948 \pm 810$ \\
Enterobacter sp. 067 & $2087 \pm 439$ \\
H. alvei 068 & $2899 \pm 606$ \\
H. alvei 071 & $3708 \pm 687$ \\
A. hydrophila 099 & $12903 \pm 192$ \\
V. harveyi BB120 & $4478 \pm 390$ \\
LB medium & $2299 \pm 384$ \\
\hline
\end{tabular}

${ }^{*}$ Average and standard deviation of data are shown. n: number of repetitions equal to 8 .

not clear why when halI was expressed in E. coli, it directed the synthesis of only two AHLs. We envision three possible scenarios that could explain these results: one in which the diversity of substrates (acyl-carrier proteins) was not present or had insufficient concentration in E. coli; also HalI could have produced levels of other AHLs that were not detected in our assays; and lastly an additional synthase is present in H. alvei. P. aeruginosa is a good example of a bacterium that contains two synthases (LasI and RhlI), both of which direct the synthesis of different AHL molecules and coordinate a complex quorum sensing cascade [6].

3.10. Detection of Autoinducer 2. Sterilized supernatant of overnight culture of $A$. hydrophila 099 in LB broth was able to induce bioluminescence production of AI-2 monitor strain $V$. harveyi BB170 (see Table 6), confirming the results of Jahid [41]. Additionally, $H$. alvei isolates 059,068 , and 071 produced AI-2 under our experimental conditions. To our knowledge this is the first report to show AI-2 production by $H$. alvei strains. In contrast, Pantoea sp. 039 and Enterobacter 067 did not produce any detectable levels of AI-2. It is noteworthy that the majority of the evaluated strains in this study are able to communicate via two different quorum sensing systems, 


\begin{tabular}{|c|c|c|c|c|c|c|c|c|}
\hline hall/halR H.alvei & AF503776 & ATTGGGTGTG & AGTAACGCCC & CTCAGGCGAT & CAGGCTGGGC & GTTGAACTCG & AACTGATTAC & 780 \\
\hline hall/halR068 & & ATTGGGTGTG & AGTAACGCCC & GTCAGGCGAT & CAGGCTGGGC & GTTGAACTCG & AACTGATTAC & 740 \\
\hline halI/halR067 & & ATTGGGTGTG & AGTAACGCCC & GTCAGGCGAT & CAGGCTGGGC & GTTGAACTCG & AACTGATTAC & 740 \\
\hline hall059 & & $----\infty--$ & $--\cdots-\cdots$ & $-\ldots-\cdots-$ & ------- & -------- & AACTGATTAC & 10 \\
\hline halI071 & & -------- & ------- & ------- & -------- & -------- & AACTGATTAC & 10 \\
\hline Clustal Consensus & & ATTGGGTGTG & AGTAACGCCC & GTCAGGCGAT & CAGGCTGGGC & GTTGAACTCG & AACTGATTAC & \\
\hline hall/halR H.alvei & AF503776 & ACCAATGCAG & TCTTAATTAC & CGCCACTGAC & ATCGGCCAGT & GCTCAAATTC & AGGCAGTGAA & 840 \\
\hline halI/halR068 & & ACCAATGCAG & TCTTAATTAC & CGCCACTGAC & ATCGGCCAGT & GCTCAAATTC & AGGCAGTGAA & 800 \\
\hline hall/halR067 & & ACCAATGCAG & TCTTAATTAC & CGCCACTGAC & ATCGGCCAGT & GCTCAAATTC & AGGCAGTGAA & 800 \\
\hline hall059 & & ACCAATGCAG & TCGTAA $--C$ C & GGCTATCGAC & ATTGGCCAAT & TAACCAGCTG & GGACTGAATA & 67 \\
\hline halI071 & & ACCAATGCAG & TCTTAATTAC & CGCCACTGAC & ATCGGCCAGT & GCTCAAATTC & AGGCAGTGAA & 70 \\
\hline Clustal Consensus & & ACCAATGCAG & TC.TAATTAC & . GC.A. . GAC & $A T . G G C C A . T$ & $\ldots$ C.A.T. & .G.C.G...A & \\
\hline halI/halR H.alvei & AF503776 & CAACCTTCAA & ATGCATTAAT & TTTTGTCGCC & ATTTTCGCCT & GACTATCAGA & GTCCGTAGGC & 900 \\
\hline hall/halR068 & & CAACCTTCAA & ATGCATTAAT & TTTTGTCGCC & ATTTTCGCCT & GACTATCAGA & GTCCGTAGGC & 860 \\
\hline halI/halR067 & & CAACCTTCAA & ATGCATTAAT & TTTTGTCGCC & ATTTTCGCCT & GACTATCAGA & GTCCGTAGGC & 860 \\
\hline halI059 & & CCACCGACTG & AAGCGGTTAT & TTTGGCTGCC & ATTTTATTCT & GGCTGACAGA & GTCTGTCG GG & 127 \\
\hline halI071 & & CAACCTTCAA & ATGCATTAAT & TTTTGTCGCC & ATTTTCGCCT & GACTATCAGA & GTCCGTAGGC & 130 \\
\hline Clustal Consensus & & C.ACC..C.. & A.GC . T.AT & TTT.G..GCC & АТTTT...СT & G.CT. . CAGA & GTC.GT.GG. & \\
\hline hall/halR H.alvei & AF503776 & AAATAGAGAA & GATAAATCCT & TTCCTCCTCA & CTCAAATATG & CCTCTTTAAG & TACCCTCACC & 960 \\
\hline halI/halR068 & & AAATAGAGAA & GATAAATCCT & TTCСTCCTCA & CTCAAATATG & ССТСTTTAAG & TACCCTCACC & 920 \\
\hline hall/halR067 & & AAATAGAGAA & GATAAATCCT & TTCСТCСTCA & CTCAAATATG & CCTCTTTAAG & TACCCT CACC & 920 \\
\hline hall059 & & AGATAAACCA & GATAAATTCG & CTCATCCTCA & CTCAGATATG & CTTCCTTAAG & CGGTTT AATT & 187 \\
\hline halI071 & & AAATAGAGAA & GATAAATCCT & TTCСТCСTCA & CTCAAATATG & CCTCTTTAAG & TACCCTCACC & 190 \\
\hline Clustal Consensus & & A. ATA.A.A & GATAAAT.C. & .TC. TCCTCA & CTCA.ATATG & C.TC.TTAAG & $\ldots . \mathrm{T} . \mathrm{A} \ldots$ & \\
\hline hall/halR H.alvei & AF503776 & TGCCAGCCAC & TGCGCTTTAG & TATTGTCAGC & ATAGCGCGGC & TAACAATCGT & ATAAATGCCG & 1020 \\
\hline hall/halR068 & & TGCCAGCCAC & TGCGCTTTAG & TATTGTCAGC & ATAGTGCGGC & TAACAATCGT & ATAAATGCCG & 980 \\
\hline hall/halR067 & & TGCCAGCCAC & TGCGCTTTAG & TATTGTCAGC & ATAGCGCGGC & TAACAATCGT & ATAAATGCCG & 980 \\
\hline hall059 & & TGCCAACCTG & AACGTTTCAA & TATTGTCAGC & ATTGCTCGGC & TGACGATAGT & GTAAATACCG & 247 \\
\hline halI071 & & TGCCAGCCAC & TGCGCTTTAG & TATTGTCAGC & ATAGCGCGGC & TAACAATCGT & ATAAATGCCG & 250 \\
\hline Clustal Consensus & & TGCCA.CC.. & .CG.TT.A. & TATTGTCAGC & $\mathrm{AT} . \mathrm{G} \ldots \mathrm{CGGC}$ & $\mathrm{T} . \mathrm{AC} \cdot \mathrm{AT} \cdot \mathrm{GT}$ & .TAAAT. CCG & \\
\hline hall/halR H.alvei & AF503776 & TTTAAGTTAT & ATTGACGAGC & GTAGTTGATC & ATCGCCAGAA & AAAGAACCTG & ACTAACAGGA & 1080 \\
\hline hall/halR068 & & TTTAAGTTAT & ATTGACGAGC & GTAGTTGATC & ATCGCCAGAA & AAAGAACCTG & ACTAACAGGA & 1040 \\
\hline hall/halR067 & & TTTAAGTTAT & ATTGACGAGC & GTAGTTGATC & ATCGCCAGAA & AAAGAACCTG & ACTAACAGGA & 1040 \\
\hline halI059 & & TTGCAACCAT & AGTGCCTAGC & ATAATTTATC & ATCGCTAAAA & ATAGTACTTG & GCTTAGCGGA & 307 \\
\hline halI071 & & TTTAAGTTAT & ATTGACGAGC & GTAGTTGATC & ATCGCCAGAA & AAAGAACCTG & ACTAACAGGA & 310 \\
\hline Clustal Consensus & & TT . A ... AT & A.TG.C.AGC & .TA.TT.ATC & ATCGC.A.AA & $A \cdot A G \cdot A C \cdot T G$ & . CT.A..GGA & \\
\hline hall/halR H.alvei & AF503776 & TATCTCTCCC & CCAGCAAATC & TCGAGCGCGA & CTTTTGTCGA & CAAAGAATCG & GCTTGATTCC & 1140 \\
\hline hall/halR068 & & TATCTCTCCC & CCAGCAAATC & TCGAGCGCGA & CTTTTGTCGA & CAAAGAATCG & GCTTGATTCC & 1100 \\
\hline halI/halR067 & & TATCTCTCCC & CCAGCAAATC & TCGAGCGCGA & CTTTTGTCGA & CAAAGAATCG & GCTTGATTCC & 1100 \\
\hline hall059 & & TATCGCTCGC & CTAACAAATC & CCTCGCGCGT & GATTTATCAA & CAAAAAATCG & GCTTGATTCT & 367 \\
\hline halI071 & & TATCTCTCCC & CCAGCAAATC & TCGAGCGCGA & CTTTTGTCGA & CAAAGAATCG & GCTTGATTCC & 370 \\
\hline Clustal Consensus & & TATC.CTC.C & C.A.CAAATC & .C..GCGCG. & . TTT.TC.A & CAAA.AATCG & GCTTGATTC. & \\
\hline hall/halR H.alvei & AF503776 & ACTTCACCGG & CTGGCAATGA & GACATCATGA & AAACAAGAGT & GGAAGGTATG & AGTAATCATA & 1200 \\
\hline halI/halR068 & & ACTTCACCGG & CTGGCAATGA & GACATCATGA & AAACAAGAGT & GGAAGGTATG & AGTAATCATA & 1160 \\
\hline halI/halR067 & & ACTTCACCGG & CTGGCAATGA & GACATCGTGA & AAACAAGAGT & GGAAGGTATG & AGTAATCATA & 1160 \\
\hline hall059 & & GTTTCACCGG & CAGGCAAAGG & CACATCCGAA & AAACAAGCCT & GAAACGTGTG & AGTAATCATA & 427 \\
\hline halI071 & & ACTTCACCGG & CTGGCAATGA & GACATCATGA & AAACAAGAGT & GGAAGGTATG & AGTAATCATA & 430 \\
\hline Clustal Consensus & & $\ldots \mathrm{TTCACCGG}$ & C. GGCAA.G. & . ACATC ...A & $\mathrm{AAACAAG} \ldots \mathrm{T}$ & G.AA.GT.TG & AGTAATCATA & \\
\hline hall/halR H.alvei & AF503776 & TTTGGCAGTT & CGAGCGGCAC & AAAACGAACA & CTGCAAATCA & ACTGCCCTTC & ATACAGACCC & 1260 \\
\hline hall/halR068 & & TTTGGCAGTT & CGAGCGGCAC & AAAACGAACA & CTGCAAATCA & ACTGCCCTTC & ATACAGACCC & 1220 \\
\hline hall/halR067 & & TTTGGCAGTT & CGAGCGGCAC & AAAACGAACA & CTGCAAATCA & ACTGCCCTTC & ATACAGACCC & 1220 \\
\hline hall059 & & TTAGGCTCAT & CCAATGGAAC & AAAGCGCACG & CTGCAGACCA & GCTGTCCCTC & ATATAAACCT & 487 \\
\hline halI071 & & TTTGGCAGTT & CGAGCGGCAC & AAAACGAACA & CTGCAAATCA & ACTGCCCTTC & ATACAGACCC & 490 \\
\hline Clustal Consensus & & $\mathrm{TT} . \mathrm{GGC} \ldots \mathrm{T}$ & C.A..GG.AC & $A A A . C G . A C$. & CTGCA.A.CA & . CTG.CC.TC & ATA.A.ACC. & \\
\hline hall/halR H.alvei & AF503776 & AAGATATAGC & GCGTGTTTGG & ATTATCAAAC & TCATCAAACT & CCATACCGCG & GTTGCAAACG & 1320 \\
\hline hall/halR068 & & AAGATATAGC & GCGTGTTTGG & ATTATCAAAC & TCATCAAACT & CCATACCGCG & GTTGCAAACG & 1280 \\
\hline halI/halR067 & & AAGATATAGC & GCGTGTTTGG & ATTATCAAAC & TCATCAAACT & CCATACCGCG & GTTGCAAACG & 1280 \\
\hline hall059 & & AGGATGTAAC & GTGTATTAGG & ATTATCAAAC & TCGTCAAACT & CCATGTCTTT & GTTGCAGACA & 547 \\
\hline halI071 & & AAGATATAGC & GCGTGTTTGG & ATTATCAAAC & TCATCAAACT & CCATACCGCG & GTTGCAAACG & 550 \\
\hline Clustal Consensus & & A. GAT.TA.C & G.GT.TT.GG & ATTATCAAAC & $\mathrm{TC} . \mathrm{TCAAACT}$ & CCAT.C... & GTTGCA.AC. & \\
\hline hall/halR H.alvei & AF503776 & ACATCCCAAC & CTAGTCGATC & GCTGAAAGT T & TTTTTTCTCA & GTCGATAAAG & TTCATCCGAA & 1380 \\
\hline hall/halR068 & & ACATCCCAAC & CTAGTCGATC & GCTGAAAGT & TTTTTTCTCA & GTCGATAAAG & TTCATCCGAA & 1340 \\
\hline hall/halR067 & & ACATCCCAAC & CTAGTCGATC & GCTGAAAGTT & TTTTTTCTCA & GTCGATAAAG & TTCATCCGAA & 1340 \\
\hline hall059 & & ACATCCCATC & CCAACCGGTC & ACTGAACGTT & TTTTTTCTCA & GTCGATAGAG & TTCATCAGAA & 607 \\
\hline hall071 & & ACATCCCAAC & CTAGTCGATC & GCTGAAAGTT & TTTTTTCTCA & GTCGATAAAG & TTCATCCGAA & 610 \\
\hline Clustal Consensus & & ACATCCCA.C & C.A. CG.TC & . CTGAA.GTT & TTTTTTCTCA & GTCGATA.AG & TTCATC.GAA & \\
\hline halI/halR H.alvei & AF503776 & CGCACTCCAT & TTAGTTCATC & ATAACTGACA & TCAAATAGTT & CAAGCATTCC & ATCACCTTGA & 1440 \\
\hline halI/halR068 & & CGCACTCCAT & TTAGTTCATC & ATAACTGACA & TCAAATAGTT & CAAGCATTCC & --------- & 1390 \\
\hline halI/halR067 & & CGCACTCCAT & TTAGTTCATC & ATAACTGACA & TCAAATAGTT & CAAGCATTCC & $-\ldots-\cdots$ & 1390 \\
\hline hall059 & & CGGACCCCAT & TCAGTTCTTC & GTAACTGACA & TCAAATAGTT & CAAGCATTCC & --------- & 657 \\
\hline halI071 & & CGCACTCCAT & TTAGTTCATC & ATAACTGACA & TCAAATAGTT & CAAGCATTCC & $-\ldots-\cdots$ & 660 \\
\hline Clustal Consensus & & CG.AC.CCAT & T.AGTTC.TC & .TAACTGACA & TCAAATAGTT & CAAGCATTCC & ATCACCTTGA & \\
\hline
\end{tabular}

Figure 6: Multiple sequence alignment of halI gene of $H$. alvei 059, 068, 071, and Enterobacter sp. 067 (this study) with halI gene of $H$. alvei (Genbank accession number AF503776). The differences of identity are indicated by gray shading. 


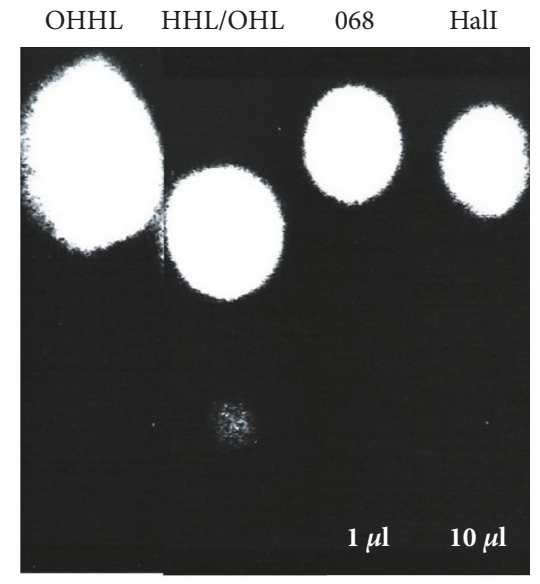

(a)

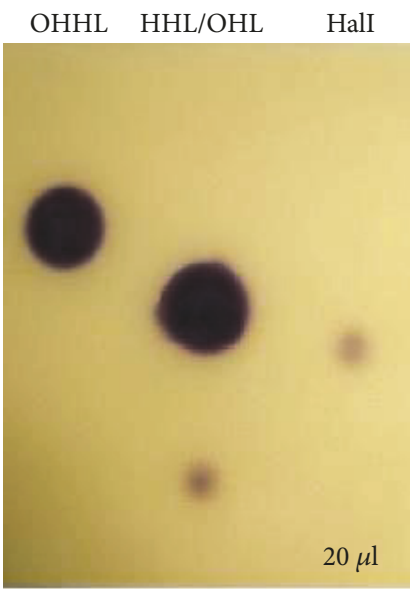

(b)

Figure 7: (a) A representative thin-layer chromatogram of HalI expression in E. coli XL1-Blue cultured in LB medium. The spots were detected with E. coli pSB403 reporter strain. Standards: N-(3-oxohexanoyl)-L-homoserine lactone (OHHL); N-(hexanoyl)-L-homoserine lactone (HHL); N-(octanoyl)-L-homoserine lactone (OHL); (068) H. alvei wild type; AHL extract diluted 50 times in ethyl acetate; (HalI) E. coli XL1-Blue harboring PQE-30Xa-halI. (b) A representative thin-layer chromatogram of HalI expression in E. coli XL1-Blue cultured in LB medium. Spots were detected with C. violaceum CV026 reporter strain. Standards: N-(3-oxohexanoyl)-L-homoserine lactone (OHHL); $\mathrm{N}$-(hexanoyl)-L-homoserine lactone (HHL); N-(octanoyl)-L-homoserine lactone (OHL); (Hall) E. coli XL1-Blue harboring pQE-30Xa-halI.
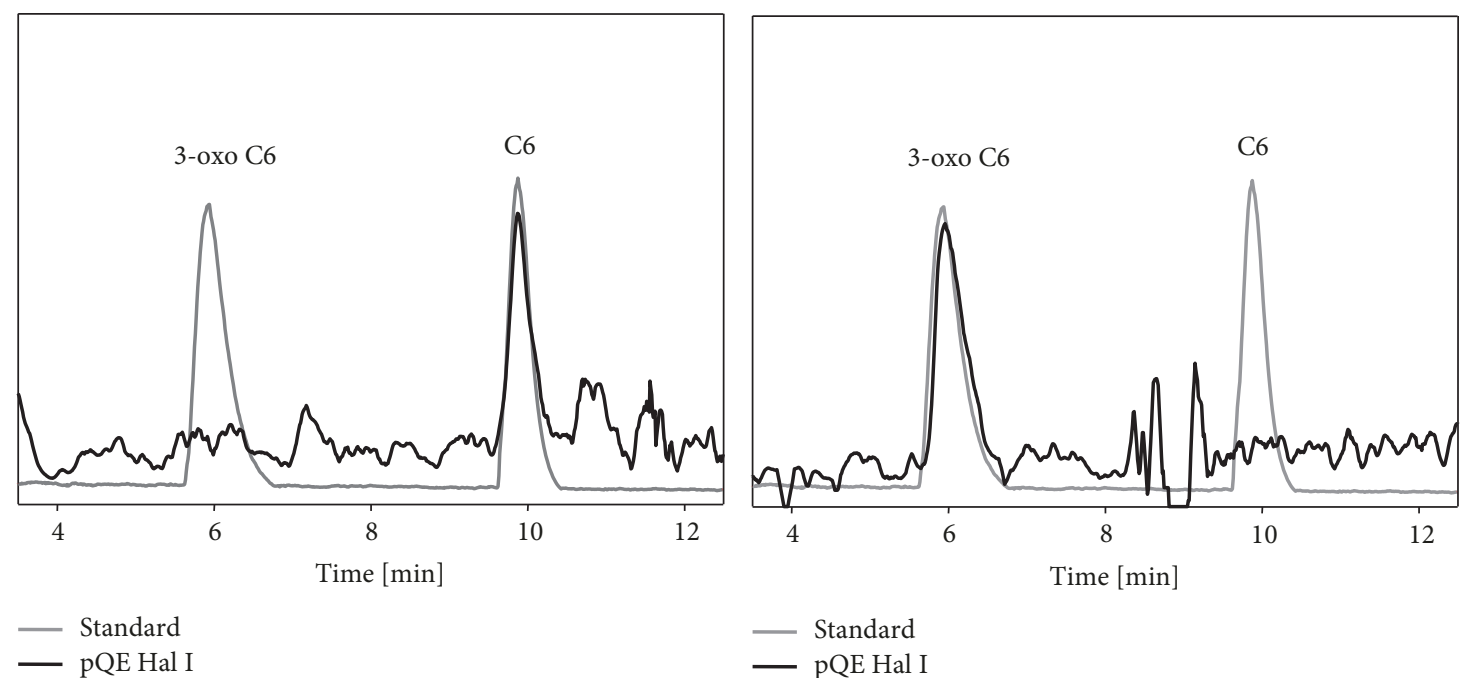

FIGURE 8: High-performance liquid chromatography-positive electrospray ionization (ESI+-) MS chromatogram showing the mass spectra for the signal molecules present in cell-free supernatant of $E$. coli XL1-Blue pQE-30Xa-halI. Signal molecule extract was obtained from overnight cell-free culture supernatant in LB minimal medium.

underscoring the importance of these signaling mechanisms in the food related environments.

\section{Conclusions}

A. hydrophila 099 presented the highest potential to spoil milk followed by $H$. alvei 068 and 071 and Enterobacter sp. 067 strains. A diverse array of AHL molecules was produced by these strains, as confirmed by different assays. The most common AHLs produced by $H$. alvei strains were C6-HSL and 3-oxo-C6-HSL, which was confirmed by ectopic expression of HalI synthase on an E. coli host. A. hydrophila 099 strongly induced the AI-2 monitor strain $V$. harveyi BB170. Taken together, these results highlight the spoilage potential of Enterobacteriaceae strains isolated from cooled raw milk and a rich array of signaling molecules produced by these microorganisms which likely influence many bacterial traits in the food environment. Quorum sensing inhibition strategies are suggested as potential barriers to milk spoilage and increased milk safety. We propose studies that use quorum sensing inhibition strategies as additional barriers in the milk processing environment. 


\section{Data Availability}

The data used to support the findings of this study are available from the corresponding author upon request.

\section{Disclosure}

This study is part of a thesis presented to Federal University of Viçosa by M.L. Martins [16].

\section{Conflicts of Interest}

The authors declare that there are no conflicts of interest regarding the publication of this paper.

\section{Acknowledgments}

We are thankful to Leo Eberl from the University of Zürich, Switzerland, for his assistance with this work. This research received grant from Conselho Nacional de Desenvolvimento Científico e Tecnológico (CNPq-Brazil grant numbers 200680/2005-6) for a doctoral scholarship provided to M.L. Martins.

\section{References}

[1] B. Dogan and K. J. Boor, "Genetic diversity and spoilage potentials among Pseudomonas spp. isolated from fluid milk products and dairy processing plants," Applied and Environmental Microbiology, vol. 69, no. 1, pp. 130-138, 2003.

[2] S. G. Machado, F. Baglinière, S. Marchand et al., "The biodiversity of the microbiota producing heat-resistant enzymes responsible for spoilage in processed bovine milk and dairy products," Frontiers in Microbiology, vol. 8, article no. 302, 2017.

[3] T. Sørhaug and L. Stepaniak, "Psychrotrophs and their enzymes in milk and dairy products: Quality aspects," Trends in Food Science Technology, vol. 8, no. 2, pp. 35-41, 1997.

[4] M. L. Martins, U. M. Pinto, K. Riedel, and M. C. D. Vanetti, "Milk-deteriorating exoenzymes from Pseudomonas fluorescens 041 isolated from refrigerated raw milk," Brazilian Journal of Microbiology, vol. 46, no. 1, pp. 207-217, 2015.

[5] W. C. Fuqua and S. C. Winans, "A LuxR-LuxI type regulatory system activates Agrobacterium Ti plasmid conjugal transfer in the presence of a plant tumor metabolite," Journal of Bacteriology, vol. 176, no. 10, pp. 2796-2806, 1994.

[6] K. Papenfort and B. L. Bassler, "Quorum sensing signalresponse systems in Gram-negative bacteria," Nature Reviews Microbiology, vol. 14, no. 9, pp. 576-588, 2016.

[7] L. Gram, A. B. Christensen, L. Ravn, S. Molin, and M. Givskov, "Production of acylated homoserine lactones by psychrotrophic members of the Enterobacteriaceae isolated from foods," Applied and Environmental Microbiology, vol. 65, no. 8, pp. 3458-3463, 1999.

[8] A. B. Christensen, K. Riedel, L. Eberl et al., "Quorum-sensingdirected protein expression in Serratia proteamaculans B5a," Microbiology, vol. 149, no. 2, pp. 471-483, 2003.

[9] U. M. Pinto, E. de Souza Viana, M. L. Martins, and M. C. D. Vanetti, "Detection of acylated homoserine lactones in gram-negative proteolytic psychrotrophic bacteria isolated from cooled raw milk," Food Control, vol. 18, no. 10, pp. 13221327, 2007.

[10] M. L. Martins, E. F. De Araújo, H. C. Mantovani, C. A. Moraes, and M. C. D. Vanetti, "Detection of the apr gene in proteolytic psychrotrophic bacteria isolated from refrigerated raw milk," International Journal of Food Microbiology, vol. 102, no. 2, pp. 203-211, 2005.

[11] S. Juretschko, G. Timmermann, M. Schmid et al., "Combined molecular and conventional analyses of nitrifying bacterium diversity in activated sludge: Nitrosococcus mobilis and Nitrospira-like bacteria as dominant populations," Applied and Environmental Microbiology, vol. 64, no. 8, pp. 3042-3051, 1998.

[12] M. M. Bradford, "A rapid and sensitive method for the quantitation of microgram quantities of protein utilizing the principle of protein dye binding," Analytical Biochemistry, vol. 72, no. 1-2, pp. 248-254, 1976.

[13] M. L. Martins, M. P. Uelinton, K. Riedel, M. C. D. Vanetti, H. C. Mantovani, and E. F. de Araújo, "Lack of AHL-based quorum sensing in Pseudomonas fluorescens isolated from milk," Brazilian Journal of Microbiology, vol. 45, no. 3, pp. 10391046, 2014.

[14] J. Sambrook, E. F. Fritsch, and T. Maniatis, Molecular cloning: a laboratory manual, Cold Spring Harbor Laboratory, Cold Spring Harbor, a laboratory manual, 2nd edition, 1989.

[15] B. L. Bassler, M. Wright, and M. R. Silverman, "Multiple signalling systems controlling expression of luminescence in Vibrio harveyi: Sequence and function of genes encoding a second sensory pathway," Molecular Microbiology, vol. 13, no. 2, pp. 273-286, 1994.

[16] C. Fuqua and S. C. Winans, "Conserved cis-acting promoter elements are required for density-dependent transcription of Agrobacterium tumefaciens conjugal transfer genes," Journal of Bacteriology, vol. 178, no. 2, pp. 435-440, 1996.

[17] C. Cha, P. Gao, Y.-C. Chen, P. D. Shaw, and S. K. Farrand, "Production of acyl-homoserine lactone quorum-sensing signals by gram-negative plant-associated bacteria," Molecular PlantMicrobe Interactions, vol. 11, no. 11, pp. 1119-1129, 1998.

[18] K. Riedel, C. Arevalo-Ferro, G. Reil, A. Görg, F. Lottspeich, and L. Eberl, "Analysis of the quorum-sensing regulon of the opportunistic pathogen Burkholderia cepacia H111 by proteomics," Electrophoresis, vol. 24, no. 4, pp. 740-750, 2003.

[19] J. Wopperer, S. T. Cardona, B. Huber, C. A. Jacobi, M. A. Valvano, and L. Eberl, "A quorum-quenching approach to investigate the conservation of quorum-sensing-regulated functions within the Burkholderia cepacia complex," Applied and Environmental Microbiology, vol. 72, no. 2, pp. 1579-1587, 2006.

[20] L. Ravn, A. B. Christensen, S. Molin, M. Givskov, and L. Gram, "Methods for detecting acylated homoserine lactones produced by Gram-negative bacteria and their application in studies of AHL-production kinetics," Journal of Microbiological Methods, vol. 44, no. 3, pp. 239-251, 2001.

[21] M. K. Winson, S. Swift, L. Fish et al., "Construction and analysis of luxCDABE-based plasmid sensors for investigating $\mathrm{N}$-acyl homoserine lactone-mediated quorum sensing," FEMS Microbiology Letters, vol. 163, no. 2, pp. 185-192, 1998.

[22] W. O. Bullock, J. M. Fernandez, and J. M. Short, "Blue: a high efficiency plasmid transforming recA Escherichia coli strain with $\beta$-galactosidase selection," Bio Techniques, vol. 5, pp. 376377, 1987.

[23] S. Schauder, K. Shokat, M. G. Surette, and B. L. Bassler, "The LuxS family of bacterial autoinducers: biosynthesis of a novel 
quorum-sensing signal molecule," Molecular Microbiology, vol. 41, no. 2, pp. 463-476, 2001.

[24] M. L. Martins, C. L. O. Pinto, R. B. Rocha, E. F. de Araújo, and M. C. D. Vanetti, "Genetic diversity of Gram-negative, proteolytic, psychrotrophic bacteria isolated from refrigerated raw milk," International Journal of Food Microbiology, vol. 111, no. 2, pp. 144-148, 2006.

[25] B. D. Oliveira, A. C. Rodrigues, B. M. I. Cardoso et al., "Antioxidant, antimicrobial and anti-quorum sensing activities of Rubus rosaefolius phenolic extract," Industrial Crops and Products, vol. 84, pp. 59-66, 2016.

[26] M. S. Medina-Martínez, M. Uyttendaele, V. Demolder, and J. Debevere, "Effect of temperature and glucose concentration on the N-butanoyl-L- homoserine lactone production by Aeromonas hydrophila," Food Microbiology, vol. 23, no. 6, pp. 534-540, 2006.

[27] J. Vivas, B. E. Razquin, P. López-Fierro, G. Naharro, and A. Villena, "Correlation between production of acyl homoserine lactones and proteases in an Aeromonas hydrophila aroA live vaccine," Veterinary Microbiology, vol. 101, no. 3, pp. 167-176, 2004.

[28] M. A. Cousin, "Presence and activity of psychrotrophic microorganisms in milk and dairy products: a review," Journal of Food Protection, vol. 45, no. 2, pp. 172-207, 1982.

[29] B. K. Khajanchi, J. Sha, E. V. Kozlova et al., "N-acylhomoserine lactones involved in quorum sensing control the type VI secretion system, biofilm formation, protease production, and in vivo virulence in a clinical isolate of Aeromonas hydrophila," Microbiology, vol. 155, no. 11, pp. 3518-3531, 2009.

[30] J. B. Bruhn, A. B. Christensen, L. R. Flodgaard et al., "Presence of acylated homoserine lactones (AHLs) and AHL-producing bacteria in meat and potential role of AHL in spoilage of meat," Applied and Environmental Microbiology, vol. 70, no. 7, pp. 4293-4302, 2004.

[31] S. Swift, M. J. Lynch, L. Fish et al., "Quorum sensingdependent regulation and blockade of exoprotease production in Aeromonas hydrophila," Infection and Immunity, vol. 67, no. 10, pp. 5192-5199, 1999.

[32] A. d. R. Ponce-Rossi, U. M. Pinto, A. d. O. B. Ribon, D. M. S. Bazzolli, and M. C. D. Vanetti, "Quorum sensing regulated phenotypes in Aeromonas hydrophila ATCC 7966 deficient in AHL production," Annals of Microbiology, vol. 66, no. 3, pp. 1117-1126, 2016.

[33] M. J. Brumlik and J. T. Buckley, "Identification of the catalytic triad of the lipase/acyltransferase from Aeromonas hydrophila," Journal of Bacteriology, vol. 178, no. 7, pp. 2060-2064, 1996.

[34] H. Hou, Y. Zhu, J. Wang et al., "Characteristics of $N$ acylhomoserine lactones produced by Hafnia alvei $\mathrm{H} 4$ isolated from spoiled instant sea cucumber," Sensors, vol. 17, no. 4, p. 772, 2017.

[35] S. Swift, A. V. Karlyshev, L. Fish et al., "Quorum sensing in Aeromonas hydrophila and Aeromonas salmonicida: identification of the Luxri homologs AhyRi and AsaRi and their cognate $N$-acylhomoserine lactone signal molecules," Journal of Bacteriology, vol. 179, no. 17, pp. 5271-5281, 1997.

[36] V. Nagar, V. Sinha, and J. R. Bandekar, "Diverse profiles of $\mathrm{N}$-acyl homoserine l-Lactones, Biofilm, virulence genes and integrons in food-borne aeromonas isolates," Journal of Food Science, vol. 80, no. 8, pp. M1861-M1870, 2015.

[37] M. J. Lynch, S. Swift, D. F. Kirke, C. W. Keevil, C. E. R. Dodd, and P. Williams, "The regulation of biofilm development by quorum sensing in Aeromonas hydrophila," Environmental Microbiology, vol. 4, no. 1, pp. 18-28, 2002.

[38] E. V. Kozlova, B. K. Khajanchi, J. Sha, and A. K. Chopra, "Quorum sensing and c-di-GMP-dependent alterations in gene transcripts and virulence-associated phenotypes in a clinical isolate of Aeromonas hydrophila," Microbial Pathogenesis, vol. 50, no. 5, pp. 213-223, 2011.

[39] L. Steindler and V. Venturi, "Detection of quorum-sensing Nacyl homoserine lactone signal molecules by bacterial biosensors," FEMS Microbiology Letters, vol. 266, no. 1, pp. 1-9, 2007.

[40] C. Fuqua, M. R. Parsek, and E. P. Greenberg, "Regulation of gene expression by cell-to-cell communication: acyl-homoserine lactone quorum sensing," Annual Review of Genetics, vol. 35, pp. 439-468, 2001.

[41] I. K. Jahid, M. F. R. Mizan, A. J. Ha, and S.-D. Ha, "Effect of salinity and incubation time of planktonic cells on biofilm formation, motility, exoprotease production, and quorum sensing of Aeromonas hydrophila," Food Microbiology, vol. 49, pp. 142151, 2015. 


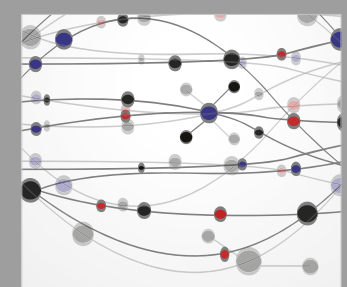

The Scientific World Journal
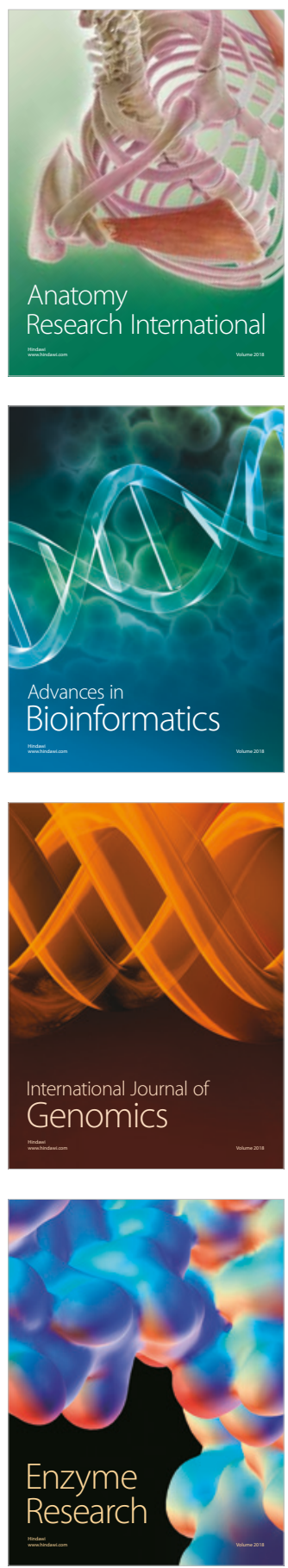
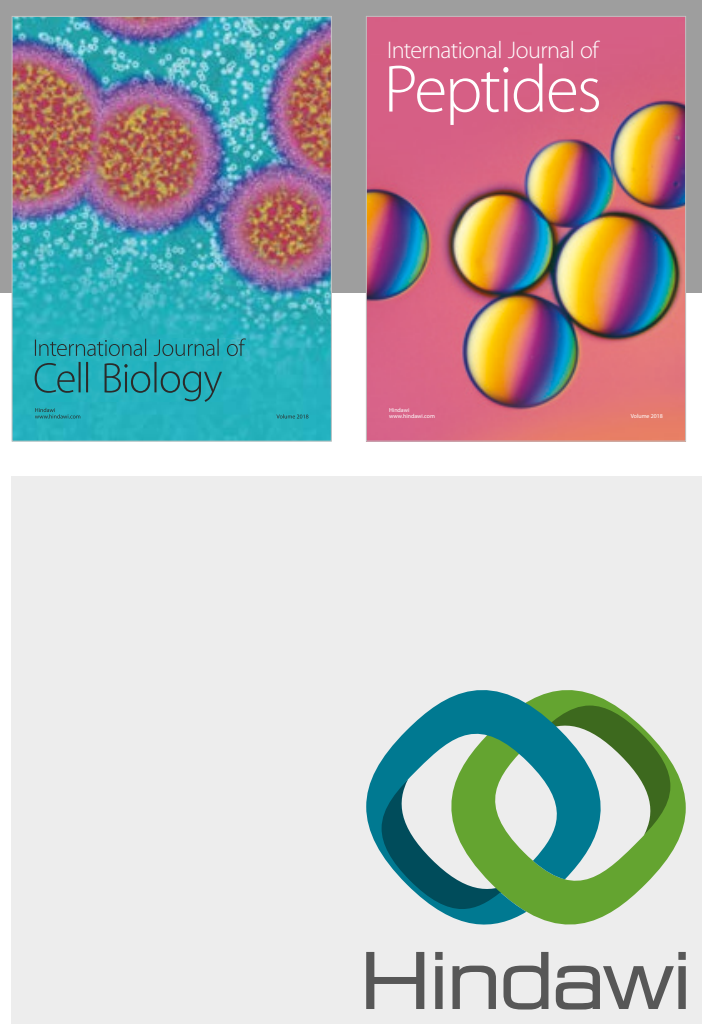

Submit your manuscripts at

www.hindawi.com
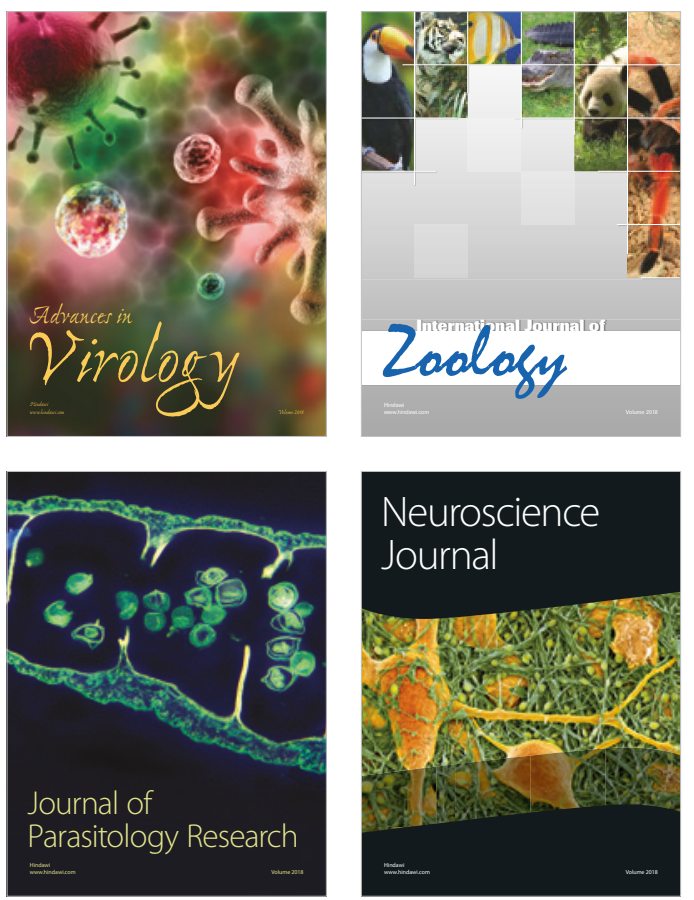
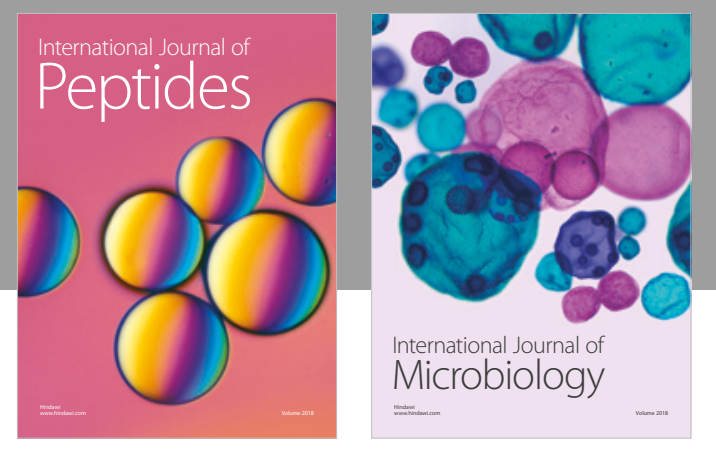

nternational Journal of Microbiology
Journal of
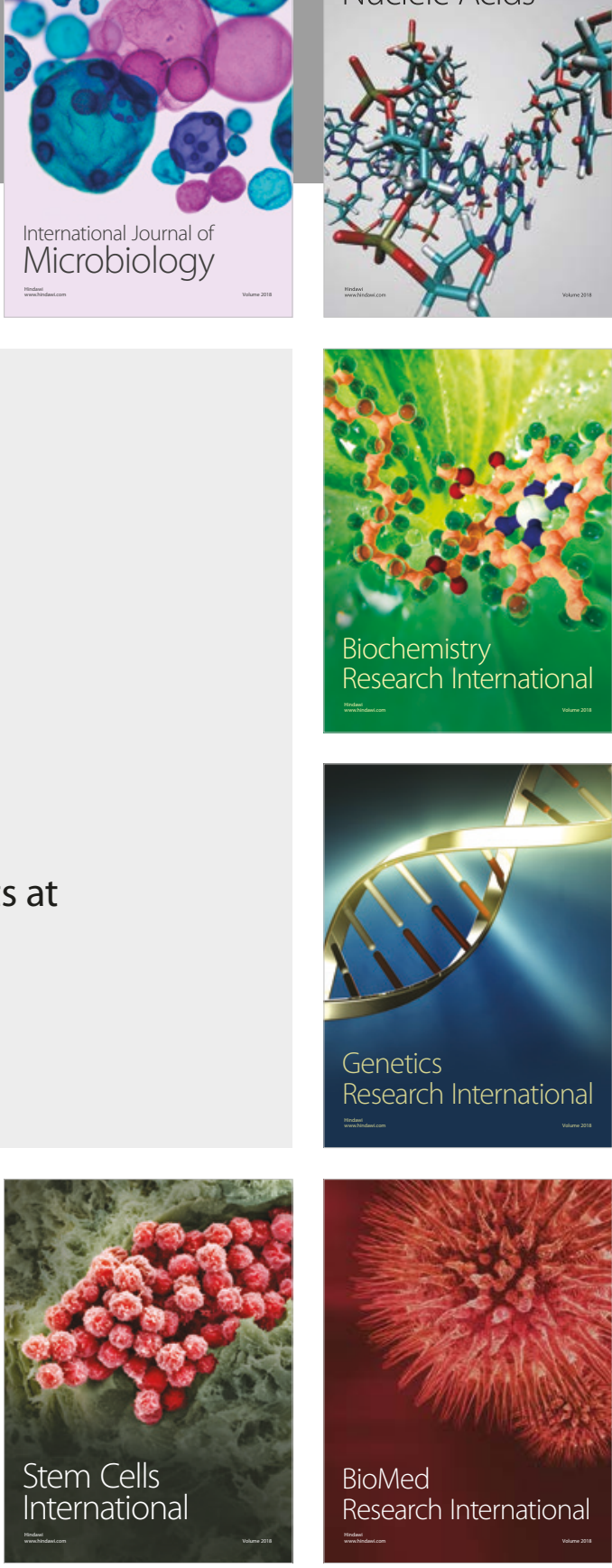
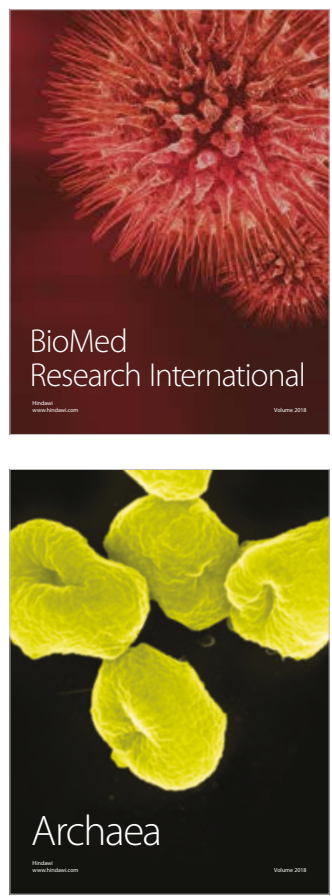